\title{
Comparison of ventricular emptying with and without a pressure gradient in patients with hypertrophic cardiomyopathy
}

\author{
ROBERT J SIEGEL, * JOHN MICHAEL CRILEY† \\ From the Departments of ${ }^{\star}$ Medicine and Radiology, UCLA School of Medicine, Cedars-Sinai Medical Center, Los \\ Angeles, California; and †Harbor-UCLA Medical Center, Torrance, California, USA
}

SUMMARY Thirty three patients with hypertrophic cardiomyopathy were studied to determine whether the presence of an intraventricular pressure gradient impaired left ventricular emptying. Patients with resting gradients had a higher mean left ventricular ejection fraction $(92(6.4) \%)$ than patients without a resting or inducible pressure gradient $(75.5(9) \%)$. The rate and degree of emptying increased when gradients $>85 \mathrm{~mm} \mathrm{Hg}$ were induced in two patients with insignificant mitral regurgitation.

If the induced gradients had been the result of obstruction a decrease in the rate or degree of ventricular emptying would be expected. Higher ejection fractions in patients with intracavitary pressure gradients as well as enhanced rate and degree of left ventricular emptying with induced gradients are inconsistent with outflow obstruction. These findings support the concept that cavity obliteration is responsible for the pressure gradient in these patients with hypertrophic cardiomyopathy.

There is a controversy about the importance of intraventricular pressure gradients in patients with hypertrophic cardiomyopathy. The presence of intracavitary left ventricular pressure gradients in patients without intraoperative or postmortem anatomical evidence of obstruction led Brock to the concept of a "functional obstruction of the left ventricle" in the late 1950s.12 Although the precise site of functional obstruction was initially thought to be a muscular sphincter or "contraction ring", ${ }^{-6}$ systolic anterior motion of the anterior mitral leaflet with apposition of the leaflet with the ventricular septum has been generally accepted as the anatomical basis for the pressure gradient and for an impediment to egress of blood from the left ventricle. ${ }^{7-12}$ The ability of the ventricle to empty rapidly in the presence of outflow tract obstruction has been attributed to late systolic mitral regurgitation. ${ }^{12}$

An alternative non-obstructive basis for the intracavitary pressure gradient in hypertrophic car-

Requests for reprints to Dr Robert J Siegel, Cardiology Division, The Cedars-Sinai Medical Center, 8700 Beverly Boulevard, Los Angeles, California 90048, USA.

Accepted for publication 27 September 1984 diomyopathy derives its theoretical premise from the work of Gauer and Gauer and Henry who recorded gradients within the hyperkinetic and hypovolaemic left ventricle in experimental animals during haemorrhagic shock and during the application of negative gravitational forces. ${ }^{13} 14$ This non-obstructive mechanism (cavitary obliteration or elimination) has been shown to be responsible for intracavitary left ventricular gradients in experimental animals and in man during various conditions which increase the contractile force or diminish the filling volume and peripheral resistance or both (for example, catecholamines, ${ }^{15}$ septic shock, ${ }^{16}$ amyl nitrite inhalation combined with the Valsalva manoeuvre or postextrasystolic potentiation. ${ }^{17}$ ) In the Gauer phenomenon, a pressure gradient develops within a hyperdynamic ventricle. The outflow tract shares the same systolic pressure as the aorta beyond, since they are in free communication. The left ventricular body generates a higher pressure as it progressively separates itself from the outflow tract while obliterating its cavity.

These diametrically opposed explanations of the pressure gradient in hypertrophic cardiomyopathy have not been satisfactorily resolved. The purpose of 
Table 1 Haemodynamic findings in 33 patients with hypertrophic cardiomypathy. Values are mean (SD)

\begin{tabular}{|c|c|c|c|c|}
\hline & Group 1 & Group 2 & Group 3 & All groups \\
\hline $\begin{array}{l}\text { Mean }(\mathrm{SD}) \text { age }(\mathrm{yr}) \\
\text { Sex }(\mathrm{M} / \mathrm{F}) \\
\text { Mean right atrial pressure }(\mathrm{mm} \mathrm{Hg})\end{array}$ & $\begin{array}{l}60(12) \\
5 / 3 \\
4 \cdot 6(4 \cdot 9)\end{array}$ & $\begin{array}{l}57 \cdot 7(19) \\
6 / 4 \\
4 \cdot 4(2 \cdot 9)\end{array}$ & $\begin{array}{l}50.5(19) \\
7 / 8 \\
4 \cdot 2(2 \cdot 4)\end{array}$ & $\begin{array}{l}55(18) \\
18 / 5 \\
4 \cdot 3(3)\end{array}$ \\
\hline $\begin{array}{l}\text { Pulmonary artery pressure }(\mathrm{mm} \mathrm{Hg}) \\
\text { Systolic } \\
\text { Diastolic } \\
\text { Left ventricular end diastolic pressure }(\mathrm{mm} \mathrm{Hg}) \\
\text { Left ventricular systolic pressure }(\mathrm{mm} \mathrm{Hg})^{\star} \\
\text { Cardiac index }\left(\mathrm{l} / \mathrm{min} \text { per } \mathrm{m}^{2}\right) \\
\text { Resting gradient }(\mathrm{mm} \mathrm{Hg}) \\
\text { Inducible gradient }(\mathrm{mm} \mathrm{Hg})\end{array}$ & $\begin{array}{l}28(8) \\
13(5) \\
15(7) \\
121(21) \\
2 \cdot 4(0 \cdot 4) \\
0 \\
0\end{array}$ & $\begin{array}{c}27(8) \\
12(6) \\
19(9) \\
142(25) \\
2.9(1 \cdot 0) \\
0+ \\
93(42)\end{array}$ & $\begin{array}{c}30(7) \\
12(4) \\
15(5) \\
189(28) \\
3 \cdot(0 \cdot 9) \\
77(36) \\
140(33)\end{array}$ & $\begin{array}{c}29(7) \\
12(5) \\
16(7) \\
158(39) \\
2.8(0.8)\end{array}$ \\
\hline
\end{tabular}

$\star$ Group $1<$ group $2<$ group 3 (p < 0.05).

†Three patients had resting gradient $\leqslant 15 \mathrm{~mm} \mathrm{Hg}$.

the current investigation was to use quantitative left ventricular angiography in patients with hypertrophic cardiomyopathy to study the relation between the pressure gradient and the ability of the ventricle to empty itself. Since previous investigations into the rate of left ventricular emptying have compared patients with hypertrophic cardiomyopathy with normal control subjects or patients with aortic stenosis, ${ }^{18-21}$ we particularly wanted to study the effect of an induced pressure gradient on left ventricular emptying in selected patients with hypertrophic cardiomyopathy without significant mitral regurgitation so that each patient served as his own control.

\section{Patients and methods}

Thirty three patients (18 men, 15 women mean (SD) age 55 (18) years) with clinical, echocardiographic, haemodynamic, and cineangiographic evidence of hypertrophic cardiomyopathy were classified into three groups on the basis of the absence of a resting or inducible intraventricular gradient (group 1), an inducible gradient (group 2), and a resting gradient of $>25 \mathrm{~mm} \mathrm{Hg}$ (group 3).

\section{CINEANGIOGRAPHY}

Cineangiography was performed with left ventricular injections of 0.5 to $0.8 \mathrm{ml} / \mathrm{kg}$ of contrast medium in 2-3 s, recorded at 30 to 60 frames per second on 35

Table 2 Severity of mitral regurgitation in 33 patients with hypertrophic cardiomyopathy. Figures are numbers of patients

\begin{tabular}{llllll}
\hline & \multicolumn{4}{l}{ Degree of mitral regurgitation ${ }^{\star}$} \\
\cline { 2 - 6 } & 0 & $1+$ & $2+$ & $3+$ & $4+$ \\
\hline $\begin{array}{c}\text { Group 1 }(\mathrm{n}=8) \\
(\text { no gradient) }\end{array}$ & 4 & 2 & 1 & 1 & 0 \\
$\begin{array}{c}\text { Goup 2 }(\mathrm{n}=10) \\
(\text { provokable gradient) }\end{array}$ & 4 & 5 & 1 & 0 & 0 \\
$\begin{array}{c}\text { Group 3 (n=15) } \\
(\text { resting gradient) }\end{array}$ & 2 & 7 & 4 & 2 & 0 \\
\hline *From Grossman.22 & & & & &
\end{tabular}

$\mathrm{mm}$ film. A calibration object was filmed at the plane of the mid ventricle for quantitation of volume. Ventricular volume was determined by the Kennedy modification of the Dodge area-length formula for the right anterior oblique projection. ${ }^{23}$ The ejection fraction was calculated in all 33 patients from normal sinus rhythm beats which did not follow premature ventricular contractions.

The left ventricular cineangiograms of two of the patients (cases 1 and 2) in whom a pressure gradient could be induced were analysed in more detail. These patients were selected because of the absence of significant mitral regurgitation and because the edges of the angiographic silhouettes were clearly delineated permitting reproducible frame by frame volume determinations. These two patients had angiograms recorded during the absence of an intraventricular pressure gradient and after a significant gradient $(>85$ $\mathrm{mm} \mathrm{Hg}$ ) had been induced. Neither of these patients had significant $(>1+)$ mitral regurgitation in that the atrium was only faintly opacified during systole and cleared completely with each diastole. ${ }^{22}$ Frame by frame determinations of ventricular volume also permitted a correlation of pressure and volume.

In the frame by frame analysis of the cineangiograms of one patient (case 1) two or more cardiac cycles were plotted to ensure reproducibility. There was a $<10 \mathrm{ml}$ difference between matched frames at the same phase of the cardiac cycle, and the filling and emptying slopes of each beat could be superimposed. A gradient was induced with an infusion of sodium nitroprusside sufficient to reduce the systolic arterial pressure to $120 \mathrm{~mm} \mathrm{Hg}$, which was this patient's normal resting pressure. The timing of systolic anterior motion-septal contact was determined in this patient from the left anterior oblique projection. ${ }^{24} \mathrm{~A}$ postectopic beat phenomenon induced a gradient of $110 \mathrm{~mm} \mathrm{Hg}$ in one patient (case 2) who had no gradient at rest.

STATISTICAL ANALYSIS

A statistical analysis of the differences in left ventricu- 

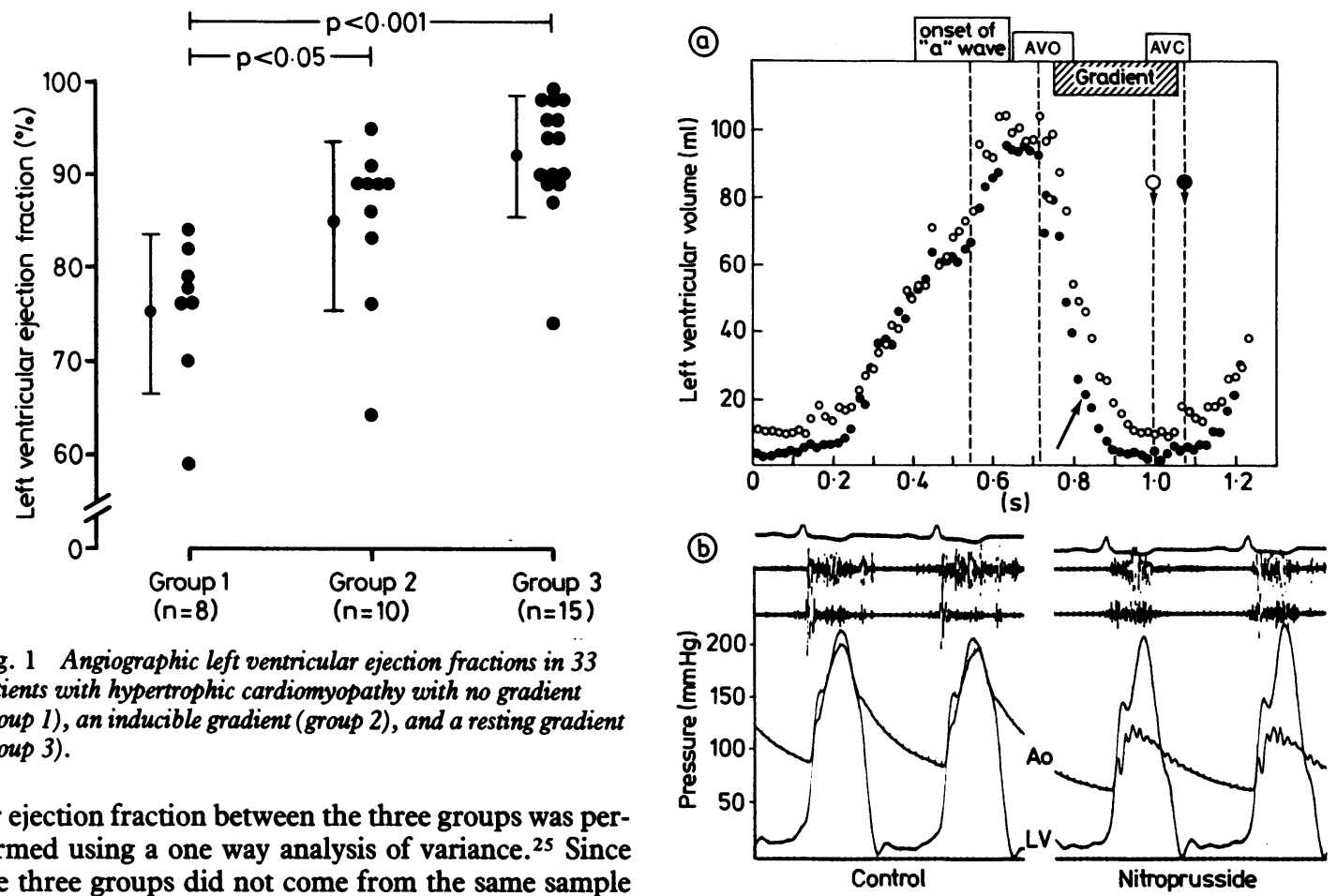

Fig. 1 Angiographic left ventricular ejection fractions in 33 patients with hypertrophic cardiomyopathy with no gradient (group 1), an inducible gradient (group 2), and a resting gradient (group 3).

lar ejection fraction between the three groups was performed using a one way analysis of variance. ${ }^{25}$ Since the three groups did not come from the same sample linear contrasts were performed using the Boneferoni correction for multiple comparisons assuming a pooled variance. ${ }^{26}$ Group comparisons of haemodynamic findings were performed using the Tukey method and the BMDP statistical package. ${ }^{26}$ All values are expressed as mean (one standard deviation).

\section{Results}

There was no significant difference in age, right heart pressures, left ventricular end diastolic pressure, degree of mitral regurgitation, or cardiac index between groups 1,2 , and 3 (Tables 1 and 2).

Figure 1 shows the resting left ventricular ejection fractions for the three groups. Group 3 had a significantly higher mean ejection fraction (92 (6.4)\%) than group $1(75.5(9) \%, p<0.001)$. Similarly, group 2 had a higher ejection fraction (85 (9)\%) than group 1 $(p<0.05)$. Thus the group with the highest mean ejection fraction had resting pressure gradients, the group in whom gradients could be induced had an intermediate mean value, and those with no gradient had the lowest mean value. Five group 2 patients had ejection fractions calculated during control and induction of a pressure gradient, and each had an increase during the gradient from $2 \%$ to $9 \%$. All three groups had significantly higher ejection fractions than the normal range $(60(8) \%)$ for our laboratory $(p<0.05)$.

Fig. 2 Case 1: angiographic frame by frame data (a) and left heart pressures (b) during control (no gradient) and during nitroprusside infusion (87 $\mathrm{mm} \mathrm{Hg}$ gradient). (a) The left ventricle empties more rapidly and completely (ejection fraction rose from 89 to 94\%) and achieves a systolic volume of $5 \mathrm{ml}$ well before aortic valve closure (AVC) (solid dot and arrow). The onset of systolic anterior motion-septal contact from the left anterior oblique cineangiogram is indicated by the inclined arrow. The aortic valve closed later in the gradient study owing to delayed relaxation of the ventricle. $(O)$ the angiographic volumes without a gradient and $(\bullet)$ with a gradient. AVO, aortic valve opening. (b) Transseptal left ventricular and retrograde aortic pressures are shown with electrocardiograms and phonocardiograms. After sodium nitroprusside infusion, no change in heart rate occurs but a $87 \mathrm{~mm} \mathrm{Hg}$ gradient develops between the left ventricle $(L V)$ and aorta $(A O)$, with the left ventricular systolic pressure remaining constant.

Figures 2 and 3 show the haemodynamic, volumetric, and angiographic data from the patient in case 1 (group 2) before and after an $87 \mathrm{~mm} \mathrm{Hg}$ pressure gradient had been induced with an infusion of sodium nitroprusside. This usually normotensive patient had a hypertensive response during cardiac catheterisation. The gradient resulted from a decrease in aortic pressure, while the left ventricular pressure and heart rate remained constant (Fig. 2b). The left ventricular ejection fraction increased from $89 \%$ to $94 \%$. Frame by frame volume analysis shows that the rate and degree of emptying increased after the gra- 


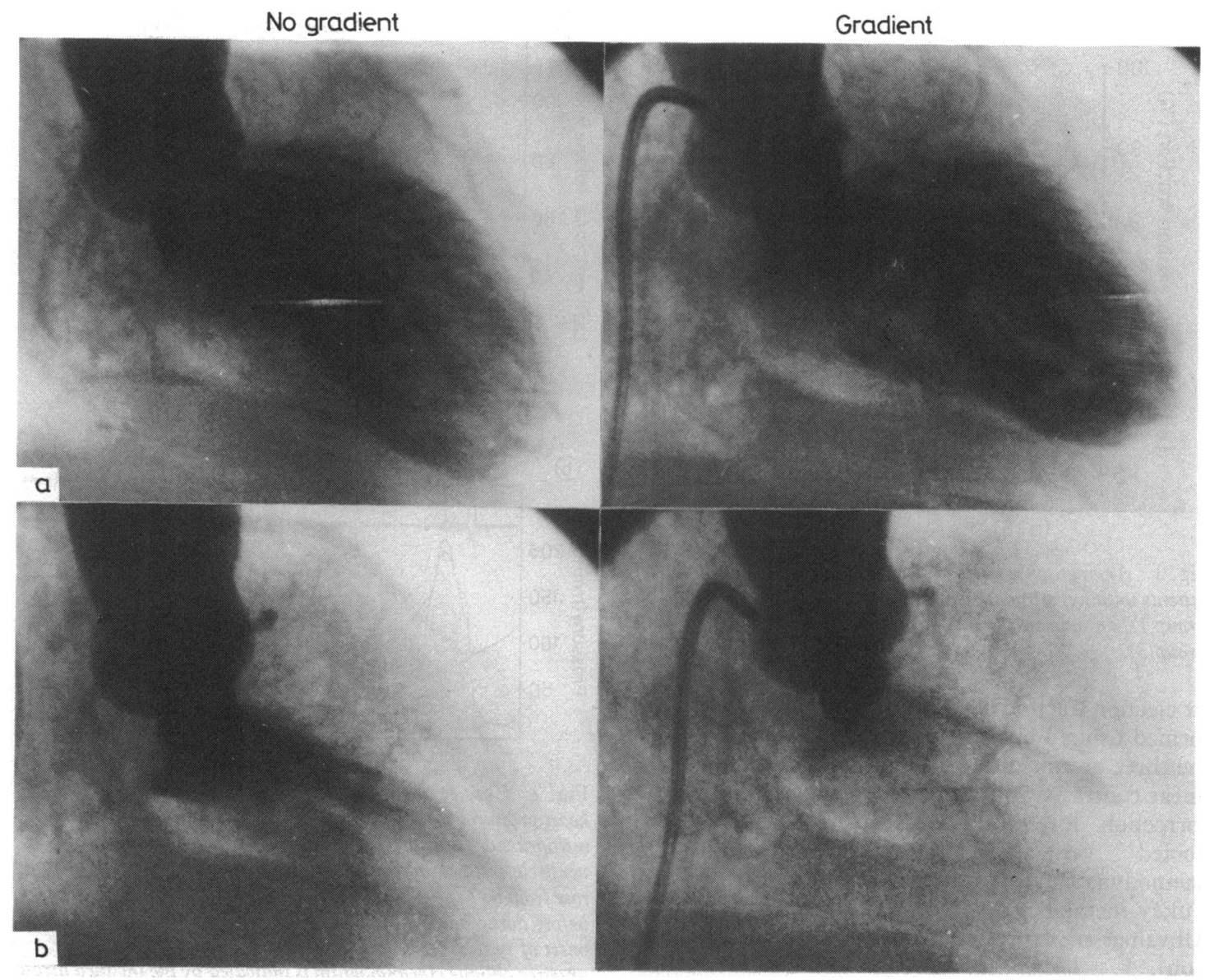

Fig. 3 Case 1: angiograms during (a) end diastole and (b) end systole with no gradient and after an $87 \mathrm{~mm} \mathrm{Hg}$ gradient was induced with nitroprusside. The degree of emptying during both studies caused obliteration of the cavity up to the level of the mitral valve and is increased after the gradient is induced.

dient was induced (Fig. 2a). The ventricle continued to empty rapidly to a small volume in the presence of a pressure gradient and systolic anterior motion-septal contact.

Although the left ventricular emptying time (aortic valve opening to aortic valve closure) is prolonged in the presence of the pressure gradient, the left ventricle achieves a miniscule end systolic volume in half of the time available and maintains an isometric contraction for the last half of systole. The delay in aortic valve closure and mitral valve opening reflects a more prolonged state of contraction or a reduced rate of relaxation or both.

Figure 3 shows the end diastolic and end systolic frames from right anterior oblique ventriculograms. The end systolic volumes were calculated to be $10 \mathrm{ml}$ (control) and $4 \mathrm{ml}$ (nitroprusside), reflecting an excessive degree of emptying under both conditions. Insignificant $(<1+)$ mitral regurgitation was seen during motion picture projection.

Figures 4 and 5 show the data from the study of the patient in case 2 (group 2). A postectopic beat and the following normal sinus beat were analysed. Before the left ventriculogram, premature ventricular contractions were induced by catheter manipulation, and the gradient between the left ventricle and femoral artery exceeded $110 \mathrm{mg} \mathrm{Hg}$ in the postectopic beat and the arterial pulse pressure decreased (Fig. 4b). Superimposition of the frame by frame plots of left ventricular emptying shows that there was more rapid and complete emptying during the postectopic beat in which the gradient was present (Fig. 4a). Trivial mitral reg- 

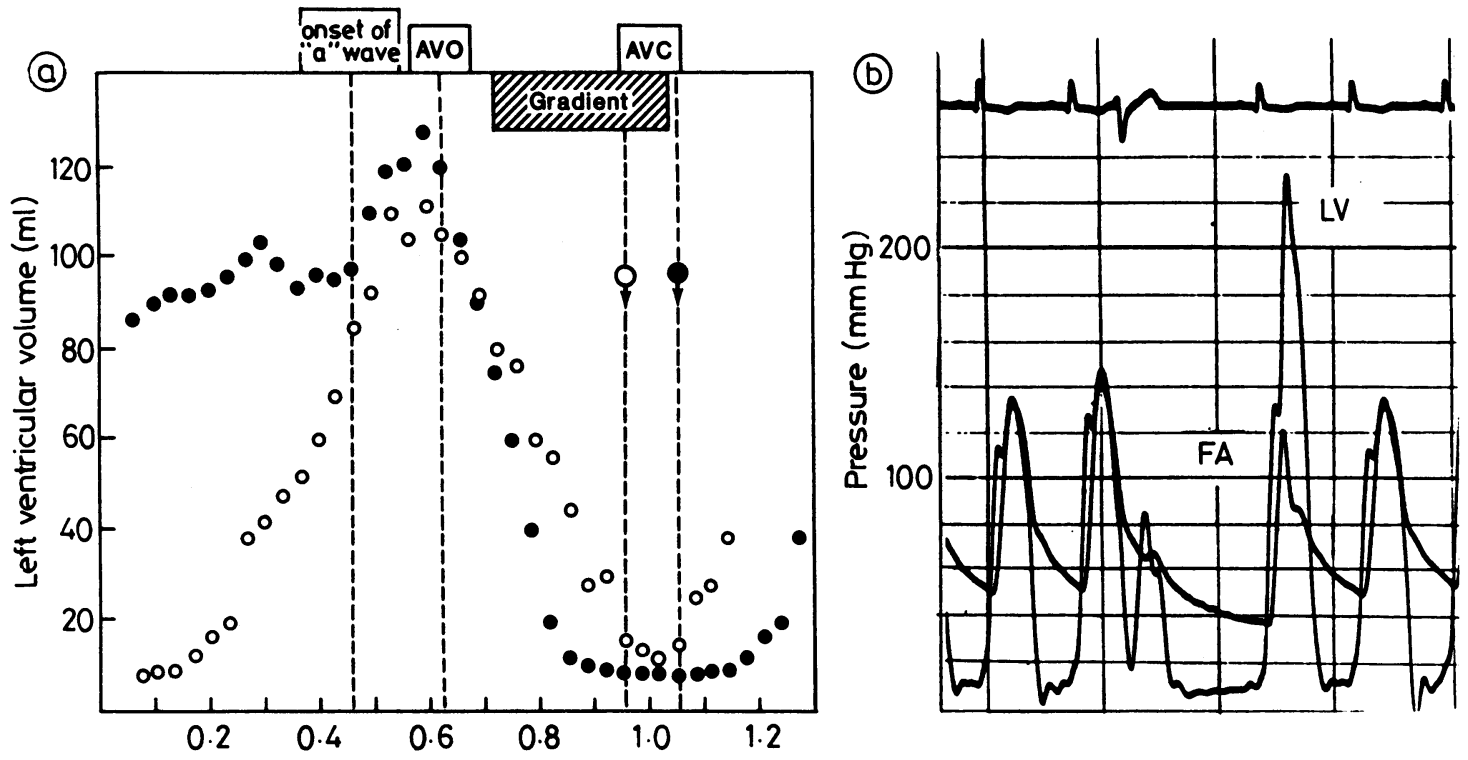

(s)

Fig. 4 Case 2: angiographic frame by frame data (a) and left heart pressures (b) during a postectopic beat and the following sinus beat. (a) The ventricle empties more rapidly but has a delayed relaxation and aortic valve closure $(A V C)$ in the postectopic beat. (O) no gradient, (O) with gradient; $A V O$, aortic valve opening. (b) Left ventricular $(L V)$ and femoral artery $(F A)$ pressures with an induced premature ventricular contraction with the same coupling interval as the premature beat during the angiographic study. The postectopic beat develops a gradient of $110 \mathrm{~mm} \mathrm{Hg}$, and the arterial pressure a "spike and dome" contour typical of hypertrophic cardiomyopathy and no increase in pulse pressure.

urgitation was seen on analysis of the motion picture but is not evident in the still frames (Fig. 5). As in the previous case, aortic valve closure and the onset of ventricular filling were delayed in the gradient beat despite the fact that the ventricle achieved a greater degree of emptying earlier in systole.

\section{Discussion}

When there is an impediment to left ventricular outflow, as in valvar aortic stenosis, there is a transvalvar pressure gradient, a reduced rate of rise of the aortic systolic pressure, a prolonged ejection time, and a slow rate of ventricular emptying. ${ }^{19}$ Despite the hindrance to outflow, the hypertrophied left ventricle in aortic stenosis may maintain a normal or increased ejection fraction, but when the obstruction is surgically relieved there is often an increase in the ejection fraction. ${ }^{27}$

The presence of a left ventricular outflow tract gradient and a prolonged ejection time in hypertrophic cardiomyopathy have been used as evidence of obstruction. ${ }^{28} 29$ An explanation of the brisk aortic pulse contour characteristic of hypertrophic cardiomyopathy has been that the ventricular outflow tract is initially widely patent and becomes progres- sively obstructed during systole. ${ }^{28}$ The rapid and complete emptying has been attributed to hyperfunction of the hypertrophied muscle and late systolic mitral regurgitation. ${ }^{30}$

It is acknowledged that the presumed obstruction in hypertrophic cardiomyopathy is not comparable to valvar aortic stenosis in that proponents of obstruction in hypertrophic cardiomyopathy have suggested that the early systolic rapid outflow followed by the absence of late systolic outflow is evidence of a "dynamic obstruction." Calculations of the effective orifice size using hydrodynamic formulas have indicated that the outflow orifice is widely patent early in systole when there is high flow and a small gradient and then progressively narrows throughout systole. Pierce and Morrow stated "in those instances where flow ceased and a pressure gradient persisted, one can only conclude that the subvalvular orifice closed completely prior to closure of the aortic valve." 28 If such an obstruction were imposed in midsystole, there would probably be an abrupt change in the rate of left ventricular emptying, but the emptying curves in the present study were not slowed when the gradient was present nor was there a significant increase in the degree of mitral regurgitation to explain the rapid and complete emptying in these cases. 


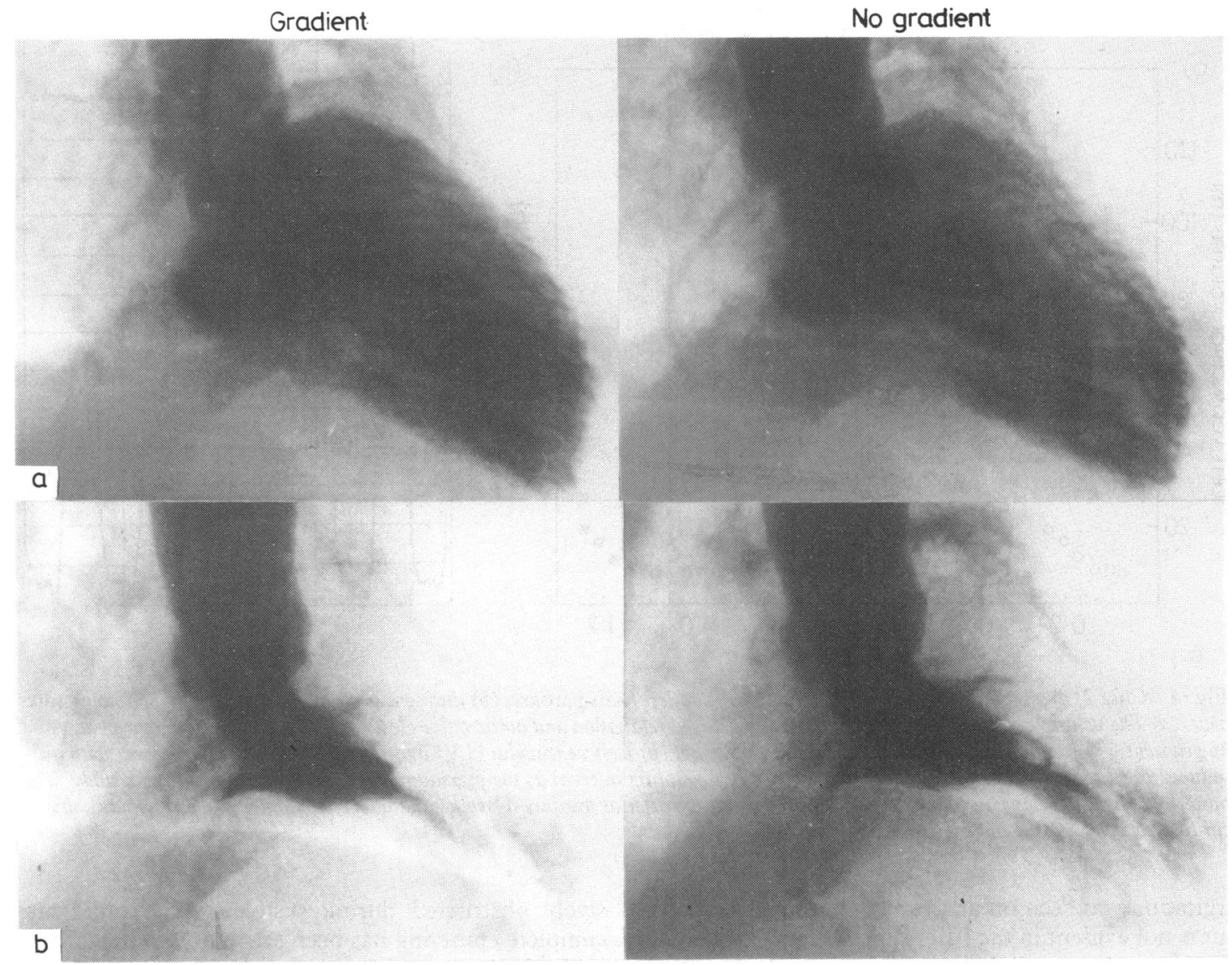

Fig. 5 Case 2: angiographic frames during (a) end diastole and (b) end systole of the postextrasystolic beat (gradient 110 $\mathrm{mm} \mathrm{Hg}$ ) and of the beat without a gradient. The degree of cavitary obliteration is increased during the postextrasystolic beat.

A non-obstructive explanation of these unique haemodynamic features of hypertrophic cardiomyopathy has been that the ventricle ejects blood rapidly and obliterates the cavity. ${ }^{18} 19$ The data from our patients are consistent with the Gauer phenomenon, in which the pressure gradient results from the progressive separation of the body and outflow tract of the left ventricle. These two regions are not separated by an obstruction but by the opposing walls of the essentially empty body of the ventricle, which contract isometrically once the intracavitary contents have been ejected. ${ }^{15}$ Cavity obliteration is therefore the antithesis of obstruction, in that the ventricle is unimpeded in its emptying. The ejection dynamics of hypertrophic cardiomyopathy have been well characterised by the work of Murgo and colleagues, who found a shortened ejection phase measured with a flow-velocity probe in the aortic root in patients with or without pressure gradients. ${ }^{21}$ Closure of the aortic valve occurred considerably after the cessation of for- ward flow, following the onset of ventricular relaxation. ${ }^{21}$ Ventricular diastolic function is known to be abnormal in hypertrophic cardiomyopathy, with a delayed relaxation and diminished distensibility, ${ }^{631^{-33}}$ and the prolonged ejection time may be more related to abnormalities of diastolic relaxation than prolongation of ejection. ${ }^{34}$

"Catheter entrapment" 24 describes artifactually high left ventricular pressures which can be recorded from catheters embedded in the myocardium which measure subendocardial myocardial tissue pressure. Although catheter entrapment has been equated with cavity obliteration, ${ }^{24}$ they are quite different phenomena. Unlike catheter entrapment blood is ejected during systole from the open end of a catheter in an obliterating cavity and the pressure decline is not delayed. ${ }^{15} 19$ The validity of high inflow tract pressure as a criterion for true obstruction ${ }^{24}$ can be questioned when the inflow tract is seen to be obliterated in angiograms (Figs. 3 and 5) and cross sectional 


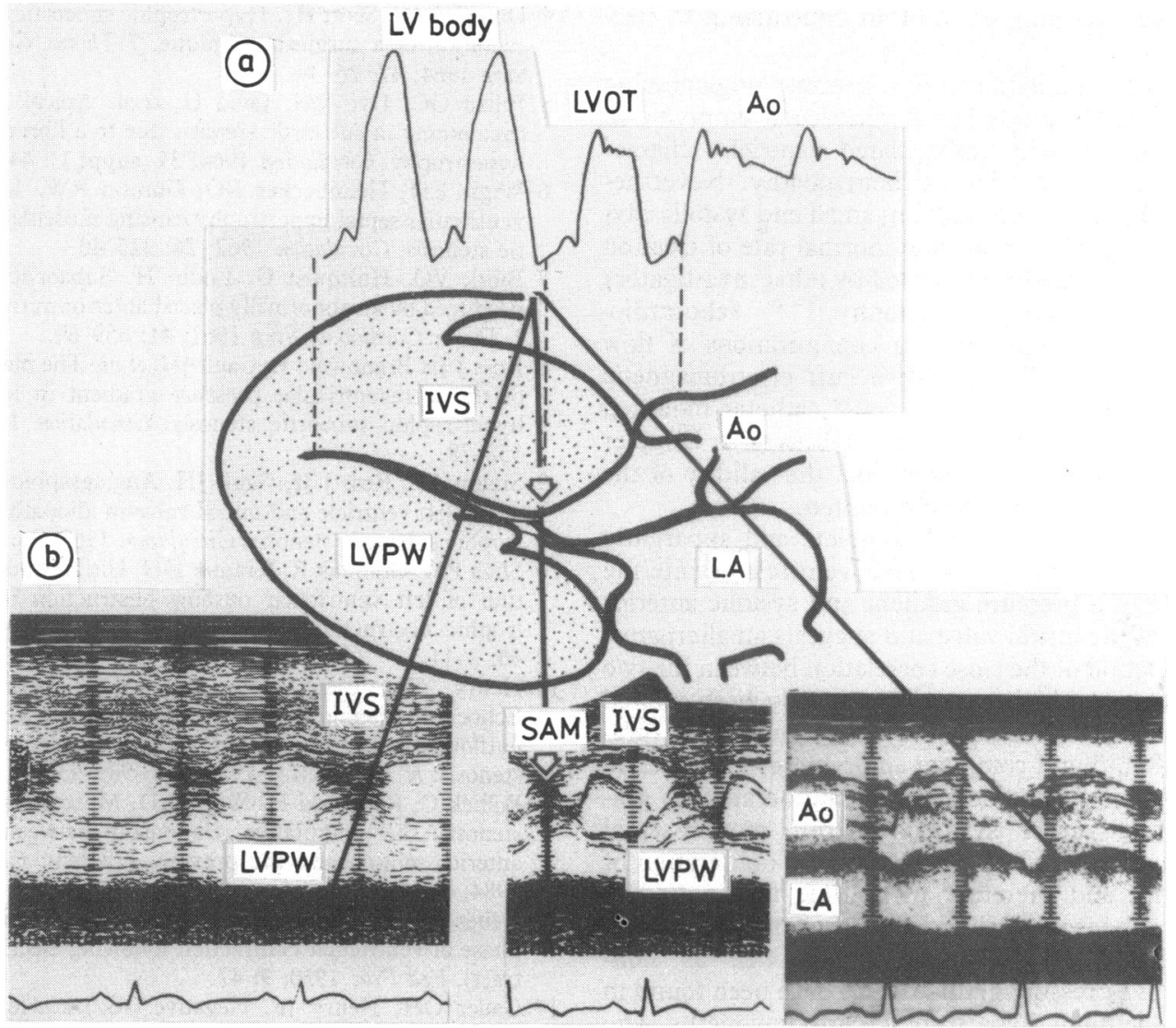

Fig. 6 (a) Diagram of the relation between the pressure gradient, systolic anterior motion (SAM), and the obliterated left ventricular $(L V)$ cavity based on the parasternal long axis cross sectional echocardiogram of a patient with hypertrophic cardiomyopathy and vertically aligned with a left heart pressure withdrawal recording so that the site of the pressure change can be seen at the junction of the obliterated body of the ventricle and the patent outflow tract (LVOT). The outflow tract is in free communication with the aorta (AO) and shares the same systolic pressure, while the pressure in the body is higher because of the progressive separation of the two left ventricular zones by cavitary obliteration. (b) Three $M$ mode echocardiograms showing systolic anterior motion (centre panel and cross sectional long axis view), which is seen to be a result of the complete emptying of the ventricle. The beam angles are shown. IVS, interventricular septum; LVPW, left ventricular posterior wall; LA, left atrium.

echocardiograms ${ }^{35}$ (Fig. 6).

The increased ejection fractions in patients with hypertrophic cardiomyopathy and the trend toward higher values in hypertrophic cardiomyopathy patients with resting pressure gradients (Fig. 1) has been previously documented using radiographic and radionuclide left ventriculography ${ }^{31} 36$ and accords with the concept of an obliterated rather than an obstructed ventricle. When the ejection fraction was compared in the same patient with and without a gradient it did not fall when the gradient was induced as would be expected with the imposition of an obstruction but rose in all instances.
Two different mechanisms were used in altering the gradient in the patients who had comparisons of left ventricular emptying in the current study. It could be argued that the patient with a postextrasystolic pressure gradient (Figs. 4 and 5) was able to overcome the "obstruction" by increasing the left ventricular pressure through the Frank-Starling effect and the increased inotropic state. Nevertheless, the left ventricular pressure and heart rate remained constant when a gradient was induced by the infusion of sodium nitroprusside in another patient (Fig. 3), and the rate and degree of emptying were enhanced in the presence of an $87 \mathrm{~mm} \mathrm{Hg}$ gradient, which would 
again belie the imposition of an impediment to ejection.

There are limitations to a contrast angiographic approach to the study of left ventricular emptying in the bizarre, heavily trabeculated ventricles characteristic of hypertrophic cardiomyopathy. Nevertheless, the high ejection fraction, small end systolic cavity size, and more rapid than normal rate of ejection have been repeatedly confirmed by other investigators using radionuclide angiography, ${ }^{36-38}$ echocardiography, ${ }^{35}$ and four different configurations of flow velocity probes: intraoperative cuff electromagnetic probes, ${ }^{28}$ dual lumen catheters, ${ }^{39}$ catheter mounted electromagnetic probes, ${ }^{21}$ and non-invasive Doppler devices. ${ }^{40}$ Thus it is unlikely that the validity of the angiographic data can be discounted.

This study shows rapid complete and apparently unimpeded emptying of the left ventricle despite the presence of a pressure gradient and systolic anterior motion of the mitral valve and suggests an alternative interpretation of the close correlation between the two phenomena ${ }^{12}$ which has conventionally been viewed as cause (systolic anterior motion) and effect (gradient). Rapid and complete emptying can apparently be the cause of systolic anterior motion and the gradient, and earlier systolic anterior motion-septal apposition could merely reflect earlier obliteration of the cavity and therefore more time for contractile energy to be expended on isometric contraction (Fig. 6). Systolic anterior motion ${ }^{41}$ as well as nonobstructive pressure gradients ${ }^{16} 17$ have been found in patients without hypertrophic cardiomyopathy who have hypovolaemic hypercontractile ventricles. We therefore suggest that evidence of hindrance to emptying should be the criterion for the presence of obstruction and not the presence of a pressure gradient or systolic anterior motion in patients with hypertrophic cardiomyopathy.

We thank Howard Staniloff, for the statistical analyses, William J French, Thasana Nivatpumin, Benjamin Rosin, and Jay Schapira, for kindly permitting the use of case material.

\section{References}

1 Brock R. Functional obstruction of the left ventricle: acquired aortic subvalvular stenosis. Guys Hospital Reports 1957; 106: 221-38.

2 Brock R. Functional obstruction of the left ventricle: acquired aortic subvalvular stenosis. Guy's Hospital Reports 1959; 108: 126-43.

3 Morrow AG, Braunwald E. Functional aortic stenosis: a malformation characterized by resistance to left ventricular outflow without anatomic obstruction. Circulation 1959; 20: 181-9.
4 Dobell ARC, Scott HJ. Hypertrophic subaortic stenosis: evolution of a surgical technique. $\mathcal{F}$ Thorac Cardiovasc Surg 1964; 47: 26-39.

5 Julian OC, Dye WS, Javid $\mathrm{H}$, et al. Apical left ventriculotomy in subaortic stenosis due to a fibromuscular hypertrophy. Circulation 1964; 31 (suppl 1): 44-56.

6 Wigle ED, Heimbecker RO, Gunton RW. Idiopathic ventricular septal hypertrophy causing muscular subaortic stenosis. Circulation 1962; 26: 325-40.

7 Björk VO, Hultquist G, Lodin H. Subaortic stenosis produced by an abnormally placed anterior mitral leaflet. f Thorac Cardiovasc Surg 1961; 41: 659-69.

8 Ross J Jr, Braunwald E, Gault JH, et al. The mechanism of the intraventricular pressure gradient in idiopathic hypertrophic subaortic stenosis. Circulation 1966; 34: 558-78.

9 Simon AL, Ross J Jr, Gault JH. Angiographic anatomy of the left ventricle and mitral valve in idiopathic hypertrophic subaortic stenosis. Circulation 1967; 36: 852-67.

10 Shah PM, Gramiak R, Kramer DH. Ultrasound localization of left ventricular outflow obstruction in hypertrophic obstructive cardiomyopathy. Circulation 1969; 40: 3-11.

11 Henry WL, Clark CE, Glancy DL, Epstein SE. Echocardiographic measurement of the left ventricular outflow gradient in idiopathic hypertrophic subaortic stenosis. $N$ Engl f Med 1973; 228: 989-93.

12 Pollick C, Rakowski H, Wigle ED. Muscular subaortic stenosis: the quantitative relationship between systolic anterior motion and the pressure gradient. Circulation 1984; 69: 43-9.

13 Gauer $\mathrm{OH}$. Evidence in circulatory shock of an isometric phase of ventricular contraction following ejection [Abstract]. Fed Proc 1950; 9: 47.

14 Gauer $\mathrm{OH}$, Henry JP. Negative (-Gz) acceleration in relation to arterial oxygen saturation, subendocardial hemorrhage and venous pressure in the forehead. Aerospace Medicine 1964; 35: 533-44.

15 White RI Jr, Criley JM, Lewis KB, Ross RS. Experimental production of intracavity pressure differences: possible significance in the interpretation of human hemodynamic studies. Am f Cardiol 1967; 19: 806-17.

16 Shabetai R. A new syndrome in hypovolemic shock: systolic murmur and intraventricular pressure gradient. Am f Cardiol 1969; 24: 404-8.

17 Grose R, Maskin C, Spindola-Franco H, Yipintsoi T. Production of left ventricular cavitary obliteration in normal man. Circulation 1981; 64: 448-55.

18 Criley JM, Lewis KB, White RI Jr, Ross RS. Pressure gradients without obstruction: a new concept of "hypertrophic subaortic stenosis". Circulation 1965; 22: 881-7.

19 Wilson WS, Criley JM, Ross RS. Dynamics of left ventricular emptying in hypertrophic subaortic stenosis: a cineangiographic and hemodynamic study. Am Heart $\mathcal{f}$ 1967; 73: 4-16.

20 Ross J Jr, Shabetai R, Curtis G, et al. Nonobstructive and obstructive hypertrophic cardiomyopathies. West $\mathcal{f}$ Med 1979; 130: 325-49.

21 Murgo JP, Alter BR, Dorethy JF, Altobelli SA, McGranahan GM Jr. Dynamics of left ventricular ejection in obstructive and nonobstructive hypertrophic cardiomyopathy. F Clin Invest 1980; 66: 1369-82. 
22 Grossman W. Cardiac catheterization and angiography. 2nd ed. Philadephia: Lea and Febiger, 1980.

23 Kennedy JW. Trenholme SE, Kaser IS. Left ventricular volume and mass from single-plane cine angiocardiogram. A comparison of antero-posterior and right anterior oblique methods. Am Heart f 1970; 80: 343-52.

24 Wigle ED, Marquis Y, Auger P. Muscular subaortic stenosis: initial left ventricular inflow tract pressure in the assessment of intraventricular pressure differences in man. Circulation 1967; 35: 1100-17.

25 Winer BJ. Statistical principles in experimental design. 2nd ed. New York: McGraw-Hill, 1971.

26 Dixon WJ, chief ed. BMDP statistical software. User's manual. Berkeley, California: University of California Press, 1983.

27 Smith N, McAnulty JH, Rahimtoola SH. Severe aortic stenosis with impaired left ventricular function and clinical heart failure: results of valve replacement. Circulation 1978; 58: 255-64.

28 Braunwald E, Lambrew CT, Rockoft SD, et al. Idiopathic hypertrophic subaortic stenosis. Circulation 1964; 30 (suppl IV): 3-119.

29 Wigle ED, Auger P, Marquis Y. Muscular subaortic stenosis: the direct relation between the intraventricular pressure difference and the left ventricular ejection time. Circulation 1967; 36: 36-44.

30 Wigle ED, Adelman AG, Auger PA, Marquis Y. Mitral regurgitation in muscular subaortic stenosis. Am f Cardiol 1969; 24: 698-706.

31 Gotsman MS, Lewis BS. Left ventricular volumes and compliance in hypertrophic cardiomyopathy. Chest 1974; 66: 498-505.

32 Sanderson JE, Gibson DG, Brown DJ, Goodwin JF. Left ventricular filling in hypertrophic cardiomyopathy: an angiographic study. $\mathrm{Br}$ Heart $\mathcal{F}$ 1977; 39: 661-70.
33 Lorell BH, Paulus WJ, Grossman W, Wynne J, Cohn PF. Modification of abnormal left ventricular diastolic properties by nifedipine in patients with hypertrophic cardiomyopathy. Circulation 1982; 65: 499-507.

34 Murgo JP, Alter BR, Dorethy JF, Altobelli SA, Craig WE, McGranahan GM Jr. The effects of intraventricular gradients on left ventricular ejection dynamics. Eur Heart $\mathcal{F}$ 1983; 4 (suppl F): 23-8.

35 Ginzton LE, Criley JM. "Obstructive" systolic anterior motion of the mitral valve in cavity obliteration [Abstract]. Circulation 1981; 64 (suppl IV): 30.

36 Manyari DE, Paulsen W, Boughner DR, Purves P, Kostuk WJ. Resting and exercise left ventricular function in patients with hypertrophic cardiomyopathy. Am Heart $\mathcal{F}$ 1983; 105: 980-7.

37 Bonow RO, Rosing DR, Bacharach SL, et al. Effect of verapamil on left ventricular systolic function and diastolic filling in patients with hypertrophic cardiomyopathy. Circulation 1981; 64: 787-96.

38 Borer JS, Bacharach SL, Green MV, et al. Effect of septal myotomy and myectomy on left ventricular systolic function at rest and during exercise in patients with IHSS. Circulation 1979; 60 (suppl 1): 82-7.

39 Hernandez RR, Greenfield JC Jr, McCall BW. Pressure-flow studies in hypertrophic subaortic stenosis. f Clin Invest 1964; 43: 401-7.

40 Kinoshita N, Nimura Y, Miyatake K, et al. Studies on flow patterns in the aortic arch in cases with hypertrophic cardiomyopathy using pulsed ultrasonic Doppler technique. $f$ Cardiogr 1978; 8: 325-32.

41 Wei JY, Weiss JL, Bulkley BH. The heterogeneity of hypertrophic cardiomyopathy: an autopsy and one dimensional echocardiographic study. Am $\mathcal{f}$ Cardiol 1980; 45: 24-32. 